\title{
Molecular characterization of the Fall armyworm, Spodoptera frugiperda (J.E. Smith) (Lepidoptera: Noctuidae) on maize in southern Rajasthan, India
}

Sakthivel Ramesh Babu ( $\sim$ babuento2018@gmail.com )

Maharana Pratap University of Agriculture and Technology https://orcid.org/0000-0002-9666-8683

Perumal Pachippan

Bharathidasan University

Raja Manoharan

Sri Karan Narendra Agriculture University

Sonika Joshi

Maharana Pratap University of Agriculture and Technology

\section{Deepika Kalyan}

Maharana Pratap University of Agriculture and Technology

Swathi Penuballi

Maharana Pratap University of Agriculture and Technology

Kalyan R K

Maharana Pratap University of Agriculture and Technology

Beerendra Singh

Maharana Pratap University of Agriculture and Technology

Mahla M K

Maharana Pratap University of Agriculture and Technology

Rokadia Pramod

Maharana Pratap University of Agriculture and Technology

\section{Research Article}

Keywords: Spodoptera frugiperda, FAW, Southern Rajasthan, Cytochrome Oxidase Subunit I, Tpi

Posted Date: July 6th, 2021

DOI: https://doi.org/10.21203/rs.3.rs-652999/v1

License: (1) (1) This work is licensed under a Creative Commons Attribution 4.0 International License.

Read Full License 


\section{Abstract}

The fall armyworm (FAW), Spodoptera frugiperda (J.E. Smith) is a polyphagous Lepidopteran pest, a native to tropical and sub-tropical America and recently it has invaded the African and Asian countries. Presently, the mitochondrial Cytochrome Oxidase Subunit I (COI) - gene based molecular characterization of FAW samples from the maize fields of southern Rajasthan has revealed the occurrence of corn and rice strains there. The occurrence of such $S$. frugiperda population of Rajasthan region could be traced its origin from the Florida-Caribbean region or African region. Further, the Tpi gene region analysis showed that the S.frugiperda forms found in the maize fields are only the corn strains. In the Indian Rajasthan populations of FAW, the Tpi-variant2 category is the highest one and is then followed by the Tpi-variant1 and $T p i$-variant3 was unique with $C$ and $T$ at $T p i e 4_{192}$ and $T p i{ }_{198} 4_{198}$, respectively. Further research is needed towards the confirmation of these tentatively identified strains of $S$. frugiperda that would in turn helpful for the proper monitoring, host-plant identification and the effective management of such pests.

\section{Introduction}

An invasive pest, the fall armyworm (FAW), Spodoptera frugiperda (J.E. Smith) (Lepidoptera: Noctuidae) is a tropical American insect that is responsible for huge economic loss (Prasanna et al. 2018). This pest had invaded Central and Western Africa during early 2016 and due to its voracious feeding nature and rapid migratory behavior it could able to rapidly spread across the Sub Saharan countries that have caused severe damages there (Goergen et al. 2016). As it is a serious pest, it could cause severe damage to almost 100 plant species representing the 27 families including the maize-crop and other graminaceous crops like millet, sorghum, rice, wheat and sugarcane (Goergen et al. 2016) and thus it would pose threat to the food security of the millions of people (De Groote et al. 2020). Montezano et al. (2018) have also reported a host range of 353 plant species representing 76 plant families like; Poaceae, Asteraceae and Fabaceae from Brazil. Over 30 countries have reported its occurrence within their borders including the island countries (Prasanna et al. 2018). The yield losses in maize ranging from $8.3 \mathrm{M}$ to 20.6 $\mathrm{M}$ tons per year have been reported from 12 maize producing countries (CABI 2016). Fall armyworm attack occurs in maize crop right from emergence to tasseling, silking and cob formation stage. This pest can reduce corn grain yield up to $34 \%$ and is estimated at U\$400 million loss annually in Brazil (Sena et al. 2003; Lima et al. 2010).

In 2018, FAW has been reported in many Asian countries like India, Yemen, Thailand, Myanmar and Sri Lanka (Liu et al. 2019), Bangladesh (Chhetri and Acharya 2019) and subsequently its spread has been reported in China, Korea, Japan and Australia (Zhang et al. 2019; Guo et al. 2018; Lee et al. 2020; Acharya et al., 2021). In India, the FAW was first time reported in Karnataka state, on maize, in May, 2018 (Sharanabasappa et al. 2018) and subsequently, within a year, the pest was found to spread in the other states viz., Andhra Pradesh, Bihar, Chhattisgarh, Gujarat, Madhya Pradesh, Maharashtra, Odisha, Rajasthan, Tamil Nadu, Telangana, West Bengal (Ramesh Babu et al. 2019), Arunachal Pradesh, Meghalaya, Manipur, Sikkim, Mizoram, Nagaland and Tripura (Firake et al. 2019). In Rajasthan, we have reported this pest for the first time in early 2019 from the Southern region of the state on winter maize 
which was confirmed by the morphological and molecular characterization (Ramesh Babu et al. 2019). However, its infestation was already been reported in some of the popular hybrids, inbreds of maize and sweet corn in the region.

The FAW species consists of morphologically identical but genetically distinct subpopulations namely the corn strain (CS) and the rice strain (RS) (Pashley et al. 1985; Prowell et al. 2004). While the corn strain's preferred feeds are; maize, sorghum and other grasses, the rice strain prefers rice and other large grasses (Pashley et al. 1986). Both these strains are region- specific and they differ in their response to bioagents like Bt and various groups of insecticides and they also exhibit different dispersal patterns (Pashley et al. 1992). Pest management strategies are formulated based on such differences between the two strains (Adamczyk et al. 1997).

Molecular genetic markers are one of the most reliable methods to differentiate the diverse strains of FAW although their morphometric features can be analyzed based on their wing shapes (Cañas-Hoyos et al. 2014). The allozymes, esterases, PCR-RFLP (DNA amplification and digestion), FR (For Rice) fragment repeats and AFLPs have been generally used to differentiate the corn strain (CS) with that of rice strain (RS) in FAW (Pashley 1986; Levy et al. 2002; Nagoshi and Meagher 2003; Prowell et al. 2004; Groot et al. 2010). Mitochondrial cytochrome oxidase subunit I (COI)-gene sequence was shown polymorphic variation between $\mathrm{C}$ and $\mathrm{R}$ strains whereas, the populations collected from the maize fields having an $\mathrm{R}$ strain in the mtDNA COI gene region (Acharya et al. 2021). Mahadeva Swamy et al. (2018) have recently studied the molecular aspect of FAW and reported the prevalence of RS FAW in maize (using mtDNA gene regions). In the present study, we have used molecular markers based on the partial regions of Cytochrome Oxidase Subunit I ( $\mathrm{CO}$ ) and also another genetic marker, the nuclear triosephosphate isomerase (Tpi) gene which is linked with Z-chromosome to confirm the species identification, differentiate the corn and rice strains and the origin of haplotypes. The single nucleotide polymorphisms (SNPs) in the Tpi gene region perhaps could form one of the reliable methods to detect the strain identity than the mtDNA COIgene regions (Nagoshi et al. 2017) and which could be also helpful to find out the host plant preference by the two strains.

\section{Materials And Methods}

During the present experiments, the standardized procedures of Levy et al. 2002; Ve'lez-Arango et al. 2012; Laura Juarez et al. 2012; Nagoshi et al. 2017 and 2018 were followed to detect FAW strains in Rajasthan populations and compared the COI haplotype pattern with the other region (Western and Eastern) populations.

\section{DNA Extraction}

Fall armyworm larvae were collected from the maize fields at various places of Rajasthan (India) during Rabi and Kharif seasons, 2019 (January to September 2019) (Table 1). The collected specimens were 
preserved at $-20^{\circ} \mathrm{C}$. Total genomic DNA was extracted using DNA Sure Tissue mini kit (Nucleo-pore, Genetix Brand, India) by following the manufacturer's instructions.

Table 1

Collection information of FAW, Spodoptera frugiperda

\begin{tabular}{|llll|}
\hline Code Name & Location of region & Collection year & Source \\
\hline BSW & Borwat Farm, Banswara Rajasthan, India & 2019 & Maize fields \\
\hline PTG & Cheniyakheri, Pratapgarh Rajasthan, India & 2019 & Maize fields \\
\hline DPRP & Punawara, Dungarpur, Rajasthan, India & 2019 & Maize fields \\
\hline DPRM & Malmata, Dungarpur, Rajasthan, India & 2019 & Maize fields \\
\hline RJD & Kunwara, Rajsamand, Rajasthan, India & 2019 & Maize Fields \\
\hline SLB & Salumber, Rajasthan, India & 2019 & Maize fields \\
\hline UDR & RCA Farm, Udaipur, Rajasthan, India & 2019 & Maize fields \\
\hline CTG & Bassi, Chittorgarh, Rajasthan, India & 2019 & Maize fields \\
\hline
\end{tabular}

\section{PCR Amplification of COI regions:}

Presently, all the PCR reactions were carried out by using C1000Touch ${ }^{\text {TM }}$ Thermal cycler of Bio-Rad, USA. The PCR amplification was performed for 50 $\mu \mathrm{L}$ containing $25 \mu \mathrm{L}$ DreamTaq PCR Master Mix (2X) (Thermo Fisher Scientific Inc.), $2 \mu \mathrm{L}$ of template DNA, 10 pmol of each forward and reverse primers (Table 2) and final volume was made by using nuclease free water. PCR was performed according to the different primers used with initial denaturation for $4 \mathrm{~min}$ at $94^{\circ} \mathrm{C}$, followed by 35 cycles of $30 \mathrm{sec}$ denaturation at $94^{\circ} \mathrm{C}, 45 \mathrm{sec}$ primers annealing at $47^{\circ} \mathrm{C}, 45 \mathrm{sec}$ initial extension at $72^{\circ} \mathrm{C}$ and a final extension of $20 \mathrm{~min}$ at $72^{\circ} \mathrm{C}$ (Ramasubramanian et al. 2016). The amplified PCR products were separated by electrophoresis in a $1.2 \%$ agarose gel containing ethidium bromide $(0.5 \mu \mathrm{g} / \mu \mathrm{L})$ for $60 \mathrm{~min}$ at $80 \mathrm{~V}(\mathrm{BIO}-$ RAD, USA) and visualized in gel documentation system (Gel Doc ${ }^{T M}$ EZ Imager, BIO-RAD, USA).

Table 2

Primer used for the identification of fall armyworm species, $S$. frugiperda in maize

\begin{tabular}{|lll|}
\hline Primer name & Forward primer \& Reverse primer & Reference \\
\hline Universal primers COI-I & LCO1490: 5'-GGTCAACAAATCATAAAGATATTGG-3' & Folmer et al (2013) \\
& HCO2198: 5'-TAAACTTCAGGGTGACCAAAAAATCA-3' & \\
\hline
\end{tabular}

\section{PCR purification, sequencing and analysis}

The PCR products were purified by using GeneJET PCR purification Kit (Thermo Fisher, Scientific Inc.) and sequenced by using ABI PRISM 3730xI Genetic Analyzer by Applied Biosystems, USA (Agile Life science Technologies India Pvt. Ltd, Pune). The obtained sequences were aligned through BioEdit sequence alignment editor (version 7.0.5.3) and homology was confirmed by using National Center for 
Biotechnology Information (NCBI)- Basic Local Alignment Search Tool (BLAST) (BLASTn, http:// www.ncbln1m.nih.gov). A phylogenic tree was graphically constructed in MEGA x program (Kumar et al. 2016).

\section{FAW Genotyping (FAW strain analysis): Restriction Site Length Polymorphism (RFLP)}

The PCR reaction was carried out for the amplification of Cytochrome Oxidase Subunit I (COI) gene of $600 \mathrm{bp}$, using the forward primer JM76 (5'-GAGCTGAATTAGG(G/A)ACTCCAGG-3') and the reverse primer JM77 (5'-ATCACCTCC(A/T)CCTGCAGGATC-3') to find out the two mitochondrial haplotypes of $S$. frugiperda based on the RFLP, according to the methods of Levy et al. (2002); Nagoshi and Meagher. (2003a); Laura Juarez et al. (2012); Cano-Calle et al. (2015).

\section{Characterization of the other $\mathrm{CO1}$ regions and Tpi gene region}

Presently, we have also used another CO/primer (apart from the universal CO/primers) to confirm and determine the strains (Corn and Rice strain) of $S$. frugiperda. To determine the regions specific haplotypes and the host strain identity, another $\mathrm{CO} /$ region was amplified with the primers $891 \mathrm{~F}$ or $893 \mathrm{~F}$ and $1472 \mathrm{R}$ or $1303 \mathrm{R}$ (Table 3). To identify the host strain and region-specific haplotypes, the COI-Il primers 891F and 1472R were used (Nagoshi et al. 2012 and 2017). The SNPs analysis at COI-II 1164 (T) and COI-II 1287 (A) identifies as rice-strain whereas, four corn-strain haplotypes (h1-h4) were found for the corn-strain group. Polymorphisms in the genetic marker, the Triosephosphate isomerase gene ( $T p i)$ also used to identify and confirm the two strains of FAW and comparable with the $\mathrm{CO} 1$ gene markers. Tpi region was amplified by using primers $412 \mathrm{~F}$ and $850 \mathrm{R}$ (Table 3). Based on the single nucleotide polymorphism (SNPs) at Tpi e4183 the two strains of $S$. frugiperda can be identified, where, the C-strain (CS) contains $\mathrm{C}$ nucleotide at 183 (Tpi e4183-C) and the R-strain (RS) contains T nucleotide at 183 (Tpi e4183 T) (Jing et al. 2019).

Table 3

Primers used for the identification of host-specific strains and haplotypes of fall armyworm, $S$. frugiperda in maize

\begin{tabular}{|c|c|c|}
\hline Primer name & Forward primer \& Reverse primer & Reference \\
\hline \multirow[t]{2}{*}{$\mathrm{COI}-\mathrm{II}$} & 891 F: 5'-TACACGAGCATATTTTACATC-3' & \multirow[t]{2}{*}{ Nagoshi et al (2017) \& 2018} \\
\hline & 1472 R: 5'-GCTGGTGGTAAATTTTGATATC-3' & \\
\hline \multirow[t]{2}{*}{ COI -III } & 893 F: 5'-CACGAGCATATTTTACATCWGCA-3' & \multirow[t]{2}{*}{ Nagoshi et al (2012) } \\
\hline & 1303 R: 5'-CAGGATAGTCAGAATATCGACG-3' & \\
\hline \multirow[t]{2}{*}{ Tpi } & 412 F: 5'-CCGGACTGAAGGTTATCGCTTG-3' & \multirow[t]{2}{*}{ Nagoshi et al (2017) \& 2018} \\
\hline & 850 R: 5'-AATTTTATTACCTGCTGTGG-3' & \\
\hline
\end{tabular}


The obtained gene sequences were submitted/deposited to/in the GenBank and the following accessions were obtained: Universal primers COI-I (MK633906; MK591010; MN486491-95; MN117927); COI -II (MZ377090- MZ377097); JM 76 \& 77 primers (MT185359-185360; MT189266-271); COI -III primers (MZ388549-MZ388550); Tpi primer (MZ418118- MZ418125).

\section{Results}

The $\mathrm{CO}$ gene sequences of $S$. frugiperda from Banswara (BSW), Dungarpur (DPRP), Chittorgarh (CTG), Salumber (SLB), Udaipur (UDR) and Pratapgarh (PTG) regions were $98-100 \%$ identical with the sequences from India (Vijayawada: GenBank MH899611 and Tirupati: GenBank MH899610 of India) and from other countries (Dominica Republic: GenBank MK3182971; Kenya: GenBank MH190445; South Africa: GenBank MF593258). A BLASTn search of DNA barcodes for another Dungarpur (DPRM) (GenBank No. MN486491) and Rajsamand (RJD) (GenBank No.MN486493) FAW populations revealed $100 \%$ nucleotide sequence resemblance with Kenyan sample (GenBank No. MH190448) and Bangladesh (GenBank No. MT073266). The sequences were $99-100 \%$ identical in sequence data and coverage. Phylogenetic analysis revealed that out of eight samples collected from maize in different places of the region, six were clustered to the $S$. frugiperda rice-strain haplotype RS9 whereas the two were clustered to the corn-strain haplotype CS1 of the United states and also with African strains, Indian strains and also with China region corn-strains (Fig. 1).

The PCR-RFLP analysis revealed that the two fragments of about 510 and 90 bp size were obtained due to cut by Mspl of PCR fragments for the corn strains but not by Sacl whereas PCR fragments of the rice strain cut by Sacl showed a reciprocal pattern by producing 450 and 150 bp fragments, but not by Mspl (Fig. 2). The corn and rice strain nucleotides differences are given in Fig. 5. In another analysis, the EcoRV enzyme digested PCR products derived from the primers COI-II: COH893F/ COL-1303R showed a single band for the corn strains (DPRM and RJD) whereas, strains of other regions showed typical diagnostic two bands which is a characteristic of rice strain (Fig. 3). The single band PCR products were purified and sequenced to confirm the absence of EcoRV site. Based on the COI-III: COI primers 891F/1472R, the FAW samples from RJD and DPRM regions were having similar polymorphic sites $\left(\mathrm{G}_{1164} ; \mathrm{G}_{1287}\right.$ haplotype) which are designated as corn strains. Similarly, the six regions of Rajasthan displayed the polymorphic sites at $\mathrm{T}_{1164} ; \mathrm{A}_{1287}$ and identified as Rice strains (Table 4). The analysis of the Tpi strain markers revealed that all the FAW populations collected from maize fields at Rajasthan were C-strain (Tpi-C haplotype) as defined by Tpi $4_{183}$ (Table 5). In Indian Rajasthan populations, Tpi-variant2 category is the highest then followed by Tpi-variant 1 and Tpi-variant3 is unique with $\mathrm{C}$ and $\mathrm{T}$ at Tpie $4_{192}$ and Tpie $4_{198}$, respectively. The comparison between INDRJ Tpi-variants with Tpi-R category identified four different

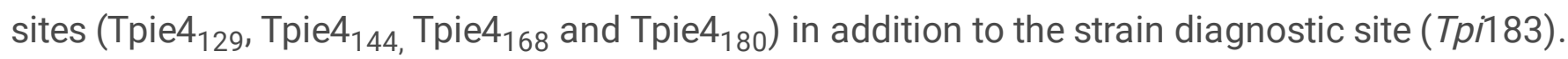


Table 4

Comparison of single nucleotide difference between India (IND) FAW populations with consensus sequences of USA (US) and Africa (AF) rice and corn haplotypes

\begin{tabular}{|c|c|c|c|c|c|c|c|c|}
\hline Haplotype/Strain & COI-II & & & & & & & Corn strain \\
\hline & 1125 & 1164 & 1176 & 1182 & 1197 & 1216 & 1287 & US-CS \\
\hline INDRJ-CS & $\mathrm{T}$ & G & $\mathrm{T}$ & C & G & $\mathrm{T}$ & G & $\begin{array}{l}A_{1164 ;} A_{1287} \\
\text { haplotype } 1(h 1) ; \\
A_{1164} ; G_{1287}\end{array}$ \\
\hline INDRJ-RS & C & $\mathrm{T}$ & C & $\mathrm{T}$ & A & A & A & haplotype 2 (h2) \\
\hline US-CS & $\mathrm{T}$ & $\mathrm{R}$ & $\mathrm{T}$ & C & G & $\mathrm{T}$ & $\mathrm{R}$ & $\begin{array}{l}\text { (Predominate in } \\
\text { South America and } \\
\text { Texas) }\end{array}$ \\
\hline US RS & C & $\mathrm{T}$ & C & $\mathrm{T}$ & A & A & A & $\begin{array}{l}\mathrm{G}_{1164} ; \mathrm{A}_{1287} \\
\text { haplotype } 3(\mathrm{~h} 3)\end{array}$ \\
\hline AF-CS & $\mathrm{T}$ & G & $\mathrm{T}$ & C & G & $\mathrm{T}$ & G & $\begin{array}{l}\mathrm{G}_{1164 ;} ; \mathrm{G}_{1287} \\
\text { haplotype } 4(\mathrm{~h} 4)\end{array}$ \\
\hline AF-RS & C & $\mathrm{T}$ & C & $\mathrm{T}$ & A & A & A & $\begin{array}{l}\text { (Florida and Greater } \\
\text { Antilles) }\end{array}$ \\
\hline
\end{tabular}


Table 5

Tpi corn and rice strain FAW haplotypes comparison of Indian with the Western Hemisphere (W.H.) and African populations

\begin{tabular}{|c|c|c|c|c|c|c|c|c|}
\hline \multirow[t]{2}{*}{ Tpi haplotypes } & \multicolumn{8}{|c|}{ Tpi single nucleiotide polymorphisms (SNPs)* } \\
\hline & 129 & 144 & 165 & 168 & 180 & 183 & 192 & 198 \\
\hline Tpi-CS* & & & & & & C & & \\
\hline TpiRS* & & & & & & $\mathrm{T}$ & & \\
\hline \multicolumn{9}{|c|}{ Tpi-CS catergory* (W.H. variants and Africa variants) } \\
\hline Tpi- C1 & C & G & C & $\mathrm{T}$ & C & C & C & C \\
\hline Tpi- C2 & C & G & C & $\mathrm{T}$ & C & C & $\mathrm{T}$ & $\mathrm{T}$ \\
\hline \multicolumn{9}{|c|}{ Tpi-RS catergory* (Africa Variant) } \\
\hline$T p i-\mathrm{R}$ & $\mathrm{T}$ & A & $\mathrm{C}$ & C & G & $\mathrm{T}$ & C & C \\
\hline \multicolumn{9}{|c|}{ Tpi-RS catergory* (W.H. Variants) } \\
\hline & $\mathrm{C}$ & G & $\mathrm{T}$ & C & $\mathrm{C}$ & $\mathrm{T}$ & & \\
\hline & C & G & $\mathrm{T}$ & C & $\mathrm{T}$ & $\mathrm{T}$ & & \\
\hline & C & G & $\mathrm{C}$ & $\mathrm{T}$ & C & $\mathrm{T}$ & & \\
\hline & C & G & A & C & C & $\mathrm{T}$ & & \\
\hline & C & G & G & C & $\mathrm{C}$ & $\mathrm{T}$ & & \\
\hline & $A$ & G & $\mathrm{T}$ & C & C & $\mathrm{T}$ & & \\
\hline & C & $A$ & $\mathrm{~T}$ & C & C & $\mathrm{T}$ & & \\
\hline & C & G & $\mathrm{C}$ & C & $\mathrm{T}$ & $\mathrm{T}$ & & \\
\hline & C & G & G & C & $\mathrm{T}$ & $\mathrm{T}$ & & \\
\hline \multicolumn{9}{|l|}{ INDRJ variants } \\
\hline Tpi variant 1 & C & G & $\mathrm{C}$ & $\mathrm{T}$ & $\mathrm{C}$ & $\mathrm{C}$ & $\mathrm{T}$ & $\mathrm{T}$ \\
\hline Tpi variant 2 & $\mathrm{C}$ & G & $\mathrm{C}$ & $\mathrm{T}$ & $\mathrm{C}$ & $\mathrm{C}$ & C & C \\
\hline Tpi variant 3 & C & G & C & T & C & C & C & T \\
\hline
\end{tabular}

\section{Discussion}


In the present study, the molecular markers of both Tpi and COI genes were used to characterize the populations of FAW collected from the maize fields of Rajasthan region. The $\mathrm{CO}$ gene sequence analysis by using universal primers revealed that all the specimens collected from the maize were of $S$. frugiperda and a similar $\mathrm{CO}$ gene fragment was earlier reported by Shylesha et al. 2018 and Mahadeva Swamy et al. 2018. The specimens collected from different regions of Rajasthan revealed that the two types of haplotypes are present in the FAW populations. This has been represented in the phylogenetic tree analysis where out of eight populations, six were clustered with the fall armyworm rice-strain specific haplotypes and two with corn-strain specific haplotypes. Earlier, Nagoshi et al. (2017) have also observed similar types of haplotypes i.e., corn and rice strains from Togo, Africa based on the CO/ region analysis. Their sequences were identical with US corn and rice-strain haplotypes. As per the present study, both the rice and corn strains are prevalent in the Indian region and they are identical to the Western hemisphere as well as with the Eastern hemisphere. In another earlier study by Nagoshi et al. (2019) found one Ecuador haplotype clustered with the rice-strain and others were similar to the corn-strain haplotype (when they analyzed the CO/gene sequences). Jing et al. (2019) have studied the phylogenetic tree which was constructed by using the Maximum likelihood method and which revealed that the majority of FAW populations belong to the corn-strain haplotype in China. Similarly, in Korea, Lee et al. (2020) reported the incidence of S.frugiperda in maize and they analyzed the haplotypes by using $\mathrm{CO}$ gene which comprised of two haplotypes based on the phylogenetic analysis.

Molecular markers have been used to differentiate the corn and rice strains of $S$. frugiperda. In the present study, PCR-RFLP method was adopted by using JM76 and JM77 primers and the amplified COI region PCR products were digested with the restriction enzymes, $\mathrm{Msp} /$ and Sacl. Out of the eight populations from different regions of Southern Rajasthan, six (BSW;UDR;CTG;PTG;DPRP;SLB) and two populations (DPRM;RJD) were identified as rice strains and corn strains, respectively. Earlier also, Machado et al. (2008) have used several molecular markers to differentiate the strains of $S$. frugiperda and they used the PCR-RFLP of the mitochondrial gene Cytochrome Oxidase Subunit I (COI) and the PCR of the tandem repeated fragment FR. Based on a PCR-RFLP product of $569 \mathrm{bp}$ of the $\mathrm{COI}$ gene that is digested with restriction enzymes, Mspl and Sacl. Two cleavage sites of 497 and 72 bp were observed in the corn strain when PCR products were digested with Mspl (Levy et al. 2002; Nagoshi and Meagher 2003), whereas when the enzyme was Sacl, two cleavage sites of 500 and 69 bp have been observed in the rice strain (Lu et al. 1994).

The analysis of another $\mathrm{CO} /$ region by using the primers $\mathrm{CO}-893 \mathrm{~F} / \mathrm{CO}-1303 \mathrm{R}$ generated a PCR product having a single EcoRV site which is a characteristic of the rice strain. PCR products of the two regions Dungarpur (DPRM) and Rajsamand (RJD) didn't have the EcoRV site which was confirmed by the sequencing of the PCR products and confirmed that the FAW populations belong to the corn strain. Nagoshi (2019) revealed that the EcoRV recognition site in the COI-RS haplotype and this strain-specific polymorphism site were not present in COI-CS haplotype in African populations.

Nagoshi et al. (2007 \& 2015) reported the geographically divided sub-groups for the corn strains of $S$. frugiperda based on differences in the mitochondrial haplotypes derived from polymorphisms at sites 
$\mathrm{CO}_{1164}$ and $\mathrm{COI}_{1287}$ in the Western hemisphere. The western hemisphere contains most of the TX-type profile whereas FL-type belongs to Florida and Caribbean regions. Populations of corn strains collected from Togo (African country) revealed the differences in haplotype pattern which was most consistent with the pattern of FL-type. In the present study, similar CO/ region primers 891F/1472R were used to study the haplotypes of $S$. frugiperda in maize. The analyzed COI-CS FAW populations were from Rajsamand (RJD) and Dungarpur (DPRM) regions that had $\mathrm{G}_{1164} \mathrm{G}_{1287}$ SNP configuration which is most consistent with the Florida-Caribbean region and Africa and Togo region corn haplotyes (Nagoshi et al. 2017). The FAW populations present in the Southern Rajasthan may be the source or originated from Sub-Saharan African region or Florida-Caribbean region.

Single Nucleotide Polymorphisms (SNPs) in the genetic marker and sex-linked Triosephosphate isomerase (Tpi) gene could also help in identifying the host-specific strains which could provide more accurate identification information of the host specific strains of $S$. frugiperda. The results of this gene can be comparable with the COI gene markers for confirmation (Nagoshi et al. 2017 \& 2018). Earlier, based on the results of such studies Nagoshi reported the presence of two strains of $S$. frugiperda in the Western as well as Eastern Hemisphere. Tpi coding region was PCR amplified using the Tpi primers $412 \mathrm{~F}$ and $850 \mathrm{R}$. The e4183 SNP varies as C or T for C-strain allele (Tpi-C) is indicated by a C183 or the R-strain (Tpi-R) is by T183. Based on this the African FAW populations showed $60 \%$ and $65 \%$ corn strains based on $\mathrm{CO}$ and Tpi markers. This indicates that the corn strains have been predominant in the FAW populations of African countries which were similar to that of Western hemisphere populations based on the Tpi gene markers. Based on the Tpi marker, all FAW populations collected from maize at Southern Rajasthan revealed that all of them were of corn-strain based on the polymorphism in the Tpi $\mathrm{e}_{183}$ site. In Indian Rajasthan populations, apart from two Tpi variants one unique variant3 was found in the FAW populations.

The present analysis of mtDNA COIgene regions confirmed that both the rice and corn strains are present in different regions of maize fields of Southern Rajasthan. The same set of FAW populations were tested with Tpi marker revealed that the corn-strain haplotypes are predominant in the collected populations of S. frugiperda from maize fields of Rajasthan. This indicates Tpi marker-based corn-strain populations showed expected associations with the host plants ie. maize than the mitochondrial markers. Therefore, this study gives a preliminary idea of the occurrence/presence of two strains of $S$. frugiperda and it is rare/unusual that both the strains have been present in the samples of maize plants of Rajasthan. $A$ more detailed survey has to be undertaken over some time by covering different regions of Rajasthan and also from different host plants. So that the exact origin and strains of $S$. frugiperda will be identified and that would have a positive impact on the timely management strategies of this pest in the future.

\section{Declarations}

\section{Acknowledgments}


The authors are highly thankful to The Director Research, MPUAT, Udaipur for constant support for research work and encouragement and the facilities established through RKVY project at Agricultural Research Station, MPUAT, Banswara are acknowledged.

\section{Author contributions}

Dr. S. Ramesh Babu contributed to the study conception and design. Material preparation, data collection and data analysis were performed by Sonika Joshi, M. Raja, Deepika Kalyan, P. Swathi, S. Ramesh Babu, R. K. Kalyan,

P. Rokadia and Beerendra Singh. The first draft of the manuscript was written by Dr. S. Ramesh Babu and all authors commented on previous versions of the manuscript. Dr. P. Perumal along with all authors read, reviewed, revised, approved the final manuscript.

\section{Compliance with ethical standards}

Conflict of interest The authors declare no conflict of interest.

\section{References}

Acharya R, Akintola AA, Malekera MJ, Kamulegeya P, Nyakunga KB, Mutimbu MK, Shrestha YK, Hemayet JSM, Hoat TX, Dao HT, et al. (2021) Genetic Relationship of Fall Armyworm (Spodoptera frugiperda) Populations That Invaded Africa and Asia. Insects 12: 439

Adamczyk JJ, Holloway JW, Leonard BR, Graves JB (1997) Susceptibility of fall armyworm collected from different plant hosts to selected insecticides and transgenic Bt cotton. J Cotton Sci 1: 21-28

CABI (2016) Datasheet Spodoptera frugiperda (fall armyworm) Invasive Species Compendium. http://www.cabi.org/isc/datasheet/29810

Cañas-Hoyos N, Marquez E, Saldamando-Benjumea Cl (2014) Differentiation of Spodoptera frugiperda (Lepidoptera: Noctuidae) Corn and Rice strains from Central Colombia: A wing morphometric approach. Ann Entomol Soc Am 107:575-581

Cano-Calle D, Arango-Isaza RE, Saldamando-Benjumea Cl (2015) Molecular identification of Spodoptera frugiperda (Lepidoptera: Noctuidae) Corn and Rice strains in Colombia by using a PCR-RFLP of the mitochondrial gene Cytochrome Oxydase I (COI) and a PCR of the gene FR (For Rice). Ann Entomol Soc Am 108: $172-180$

Chhetri LB, Acharya B (2019) Fall armyworm (Spodoptera frugiperda) : A threat to food security for south Asian country : Control and management options : A review. Fmg Mngmt 4:38-44

De Groote, D., Kimenju, S.C., Munyua, B., Palmas, S., Kassie, M. \& Bruce, A. (2020). Spread and impact of fall armyworm (Spodoptera frugiperda JE Smith) in maize production areas of Kenya. Agric Ecosyst 
EPPO (2015) Spodoptera littoralis, Spodoptera litura, Spodoptera frugiperda, Spodoptera eridania. EPPO Bulletin 45: 410-444

Firake DM, Behere GT, Babu S, Prakash N (2019) Fall armyworm: Diagnosis and management (An extension pocket book) ICAR Research Complex for NEH Region, Umiam-793 109, Meghalaya, India. pp 48

Folmer O, Black M, Hoeh W, Lutz R, Vrijenhoek R (1994) DNA primers for amplification of mitochondrial cytochrome $\mathrm{c}$ oxidase subunit I from diverse metazoan invertebrates. Mol Mar Biol Biotechnol 3: 294-299

Goergen G, Lava KP, Sagnia B, Sankung, Abou T, Manuele T (2016) First report of outbreaks of the fall armyworm Spodoptera frugiperda (JE Smith) (Lepidoptera, Noctuidae), a new alien invasive pest in West and Central Africa. PLoS One 11:0165632

Groot AT, Marr M, Heckel DG, Schofl G (2010) The roles and interactions of reproductive isolation mechanisms in fall armyworm (Lepidoptera: Noctuidae) host strains. Ecol Entomol 35: 105-118

Guo J, Zhao J, He K, Zhang F, Wang Z (2018) Potential invasion of the crop-devastating insect pest fall armyworm Spodoptera frugiperda to China. Plant Prot 44: 1-10

Jing DP, Guo JF, Jiang YY, Zhao JZ, Sethi A, He KL, Wang ZY (2019) Initial detections and spread of invasive Spodoptera frugiperda in China and comparisons with other noctuid larvae in cornfields using molecular techniques. Insect Sci 27:780-790

Juárez ML, Murúa MG, García MG, Ontivero M, Vera MT, Vilardi JC, Groot AT, Castagnaro AP et al (2012) Host association of Spodoptera frugiperda (Lepidoptera: Noctuidae) corn and rice strains in Argentina, Brazil, and Paraguay. J Econ Entomol 105: 573-82

Kumar S, Stecher G, Tamura K (2016) MEGA7: Molecular evolutionary Genetics Analysis Version 7.0 for bigger datasets. Mol Biol Evol 33: 1870-4

Laura Juarez M, Gabriela Murua M, Gabriela Garcia M, Marta Ontivero, Teresa Vera M, Vilardi, JC, Groot AT, Castagnaro AP, Gerardo Gastaminza, Educardo Willink (2012) Host Association of Spodoptera frugiperda (Lepidoptera: Noctuidae) Corn and Rice Strains in Argentina, Brazil, and Paraguay. J Econ Entomol 105: 573-582

Lee GS, Seo BY, Lee JH, Kim HJ, Song JH, Lee WH (2020) First report of the fall armyworm, Spodoptera frugiperda (Smith, 1797) (Lepidoptera, Noctuidae), a new migratory pest in Korea. Korean J Appl Entomol 59: 73-78

Levy CH, Garcia-Maruniak A, Maruniak J (2002) Strain identification of Spodoptera frugiperda (Lepidoptera: Noctuidae) insects and cell line: PCR- RFLP of cytochrome oxidase c subunit I gene. Fla 
Lima MS, Silva PSL, Oliveira OF, Silva KMB, Freitas FCL (2010) Corn yield response to weed and fall armyworm controls. Planta Daninha 28:103-111

Liu H, Lan T, Fang D, Gui F, Wang H, Guo W, Cheng X, Chang Y, Shuqi He, Lihua Lyu, Sunil Kumar Sahu, Le Cheng, Haimeng Li, Ping Liu, Guangyi Fan, Tongxian Liu, Ruoshi Hao, Haorong Lu, Bin Chen, Shusheng Zhu, Zhihui Lu, Fangneng Huang, Wei Dong, Yang Dong, Le Kang, Huanming Yang, Jun Sheng, Youyong Zhu, Xin Liu (2019) Chromosome level draft genomes of the fall armyworm, Spodoptera frugiperda (Lepidoptera: Noctuidae), an alien invasive pest in China. BioRxiv 671560

Lu YJ, Kochert GD, Isenhour DJ, Adang MJ (1994) Molecular characterization of a strain-specific repeated DNA sequence in the fall armyworm Spodoptera frugiperda (Lepidoptera: Noctuidae). Insect Mol. Biol 3: 123-130

Ma J, Wang YP, Wu MF, Gao BY, Liu J, Lee GS, Otuka A, Hu Gao (2019) High risk of the Fall Armyworm invading into Japan and the Korean Peninsula via overseas migration. J. Appl. Entomol 00:1-10

Machado V, Wunder M, Baldissera VD, Oliveira JV, Fiu'za LM, Nagoshi RN (2008) Molecular characterization of host strains of Spodoptera frugiperda (Lepidoptera: Noctuidae) in Southern Brazil. Ann Entomol Soc Am 101: 619-626

Mahadeva Swamy H, Ashoka R, Kalleshwaraswamy CM, Sharanabassapa, Prasad YG, Maruthi MS, Shashank PR, Norem ID, Anusha Surakasula, Adarsha S, Srinivas A, Srinivasa Rao, Vidyasekhar, Shali Raju M, Shyam Sunder Reddy M, Nagesh, SN (2018) Prevalence of "R" strain and molecular diversity of fall armyworm Spodoptera frugiperda (J. E. Smith) (Lepidoptera: Noctuidae) in India. Indian J Entomol 80: 544-553

Montezano DG, Specht A, Sosa-Gómez DR, Roque-Specht VF, Sousa-Silva JC, Paula-Moraes SV, Peterson JA, Hunt TE (2018) Host plants of Spodoptera frugiperda (Lepidoptera: Noctuidae) in the Americas. Afr Entomol 26: 286-300

Nagoshi RN (2019) Evidence that a major subpopulation of fall armyworm found in the Western Hemisphere is rare or absent in Africa, which may limit the range of crops at risk of infestation. PLoS One 14: e0208966

Nagoshi RN, Meagher RL (2003) FR tandem-repeat sequence in fall armyworm (Lepidoptera: Noctuidae) host strains. Ann Entomol Soc Am 96: 329-335

Nagoshi RN, Meagher RL (2004) Seasonal distribution of fall armyworm (Lepidoptera: Noctuidae) host strains in agricultural and turf grass habitats. Environ Entomol 33: 881-889

Nagoshi RN, Silvie P, Meagher RL (2007) Comparison of haplotype frequencies differentiate fall armyworm (Lepidoptera: Noctuidae) corn-strain populations from Florida and Brazil. J. Econ. 
Nagoshi RN, Goergen G, Tounou KA, Agboka K, Koffi D, Meagher RL (2018) Analysis of strain distribution, migratory potential, and invasion history of fall armyworm populations in northern Sub-Saharan Africa. Sci Rep 8: 3710

Nagoshi RN, Koffi D, Agboka K, Tounou KA, Banerjee R, Jurat-Fuentes JL, Meagher RL (2017) Comparative molecular analyses of invasive fall armyworm in Togo reveal strong similarities to populations from the eastern United States and the Greater Antilles. PLoS One 12: e0181982

Nagoshi RN, Murúa G, Hay-Roe M, Juárez ML, Willink E, Meagher RL (2012) Genetic characterization of fall armyworm (Lepidoptera: Noctuidae) host strains in Argentina. J. Econ. Entomol 105: 418-428

Nagoshi RN, Nagoshi BY, Canarte E, Navarrete B, Solorzano R, Garces-Carrera S (2019) Genetic characterization of fall armyworm (Spodoptera frugiperda) in Ecuador and comparisons with regional populations identify likely migratory relationships. PLoS One 14: e0222332

Nagoshi RN, Rosas-García NM, Meagher RL, Fleischer SF, Westbrook JK, Sappington TW, Hay-Roe M, Thomas JMG, Gabriela MM (2015) Haplotype Profile Comparisons between Spodoptera frugiperda (Lepidoptera: Noctuidae) populations From Mexico with those from Puerto Rico, South America, and the United States and their implications to migratory Behavior. J. Econ. Entomol 108: 135-144

Nagoshi RN, Koffi D, Agboka K, Tounou KA, Banerjee R, Jurat-Fuentes JL, et al. (2017) Comparative molecular analyses of invasive fall armyworm in Togo reveal strong similarities to populations from the eastern United States and the Greater Antilles. PLoS ONE 12: e0181982

Otim MH, Tay WT, Walsh TK, Kanyesigye D, Adumo S, Abongosi J, Ochen S, Sserumaga J. et al (2018) Detection of sister-species in invasive populations of the fall armyworm Spodoptera frugiperda (Lepidoptera: Noctuidae) from Uganda. PLos One 13: e0194571

Pashley DP (1986) Host-associated genetic differentiation in fall armyworm (Lepidoptera: Noctuidae): a sibling species complex?. Ann Entomol Soc Am 79: 898-904

Pashley DP, Johnson SJ, Sparks AN (1985) Genetic population structure of migratory moths: the fall armyworm (Lepidoptera: Noctuidae). Ann Entomol Soc Am 78: 756-762

Pashley DP, Hammond AM, Hardy TN (1992) Reproductive isolating mechanisms in fall armyworm host strains (Lepidoptera: Noctuidae). Ann Entomol Soc Am 85: 400-405

Pogue MA (2002) World revision of the genus Spodoptera Guene'e (Lepidoptera: Noctuidae). Mem Am Entomol Soc 43: 1-202

Prasanna BM, Joseph HE, Regina E, Virginia MP (2018) Fall armyworm in Africa: A Guide for Integrated Pest Management First Edition. Mexico, CDMX, CIMMYT, pp.120. 
Prowell DP, McMichael M, Silvain JF (2004) Multilocus genetic analysis of host use, introgression, and speciation in host strains of fall armyworm (Lepidoptera: Noctuidae). Ann Entomol Soc Am 97: 10341044

Ramasubramanian T, Singaravelu B, Appunu C (2016) Training Manual on techniques In Insect Molecular Biology and Toxicology, ICAR-Sugarcane Breeding Institute, Coimbatore, pp 100.

Ramasubramanian T, Ramaraju, Nirmala R (2016) COI gene based species diagnostic kit for sugarcane scale insect, Melanaspis glomerata (Green) (Homoptera: Diaspididae). Sugar Tech 18: 441-446

Ramesh Babu S, Kalyan RK, Joshi S, Balai CM, Mahla MK, Rokadia P (2019) Report of an exotic invasive pest the fall armyworm, Spodoptera frugiperda (JE Smith) on maize in Southern Rajasthan. J Entomol Zool Stud 7:1296-1300

Sena DG, Pinto F, De Queiroz DM, Viana PA (2003) Fall armyworm damaged maize plant identification using digital images. Biosyst Eng 85:449-454

Sharanabasappa, Kalleshwaraswamy CM, Maruthi MS, Pavithra HB (2018) Biology of invasive fall armyworm Spodoptera frugiperda (JE Smith) (Lepidoptera: Noctuidae) on maize. Indian J Entomol 80: $540-543$

Shylesha AN, Jalali SK, Gupta A, Varshney R, Venkatesan T, Shetty P, Ojha R, Ganiger, P.C. et al. (2018). Studies on new invasive pest Spodoptera frugiperda (JE Smith) (Lepidoptera: Noctuidae) and its natural enemies. J Biol Control 32: 145-151

Ve'lez-Arango AM, Arango RE, Villanueva D, Aguilera E, Saldamando $\mathrm{Cl}$ (2008) Identification of Spodoptera frugiperda biotypes (Lepidoptera: Noctuidae) through using mitochondrial and nuclear markers. Rev Colomb Entomol 34: 145-150

Zhang L, Jin MH, Zhang DD, Jiang YY, Liu J, Wu KM (2019) Molecular identification of Spodoptera frugiperda in Yunnan province. Plant Prot 45: 19-24

\section{Figures}




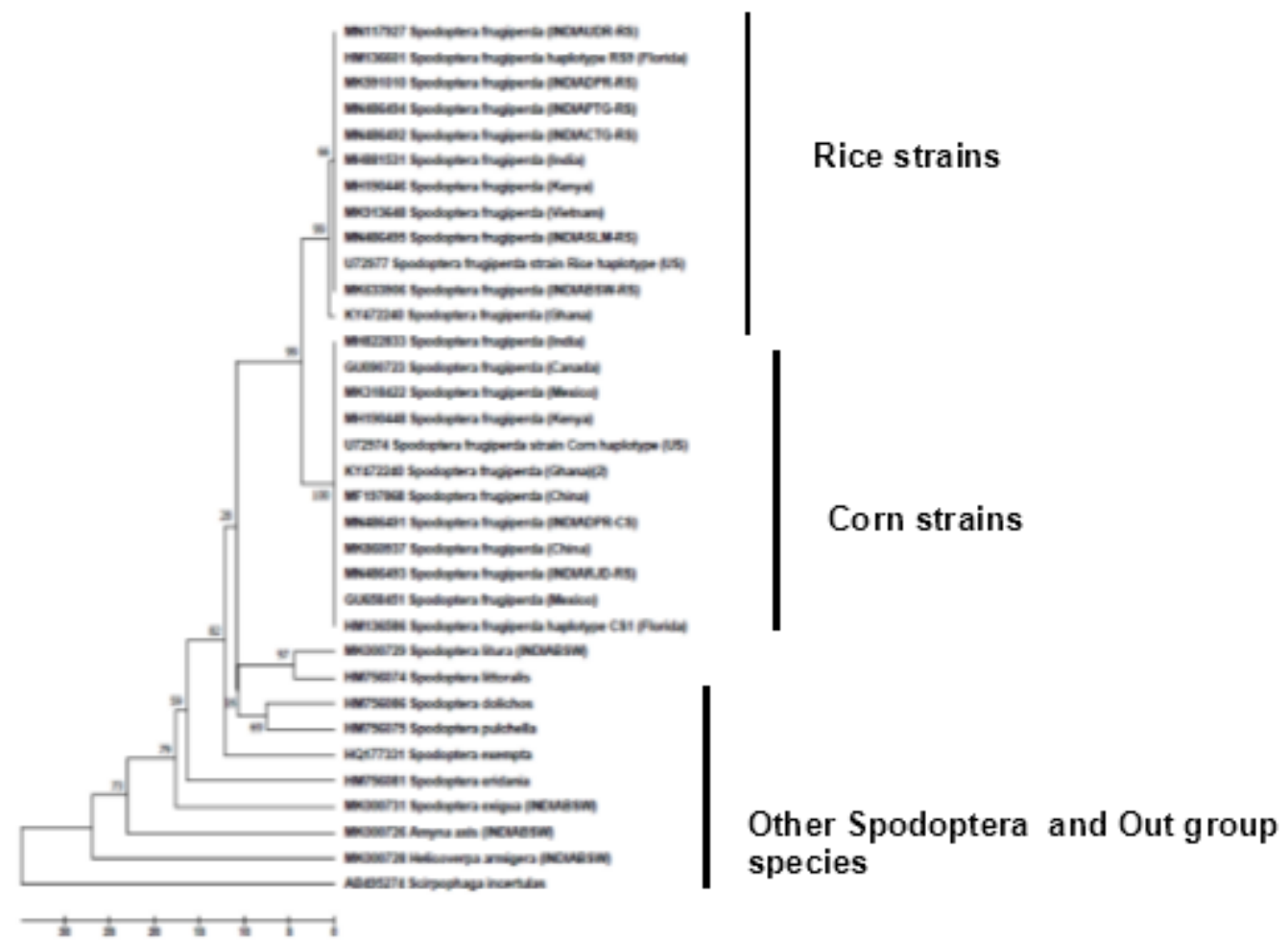

Fig. 1 The analysis involved 34 nucleotide sequences and conducted in MEGA 6. The evolutionary history was inferred using the UPGMA method. The percentage of replicate trees in which the associated taxa clustered together in the bootstrap test (1000 replicates) is shown next to the branches. The tree is drawn to scale, with branch lengths in the same units as those of the evolutionary distances used to infer the phylogenetic tree. (Spodoptera species found in GenBank: S. dolichos (HM756086); S. littoralis (HM756074); S. exempta (HQ177331); S. eridania (HM756081)

\section{Figure 1}

[See figure] 

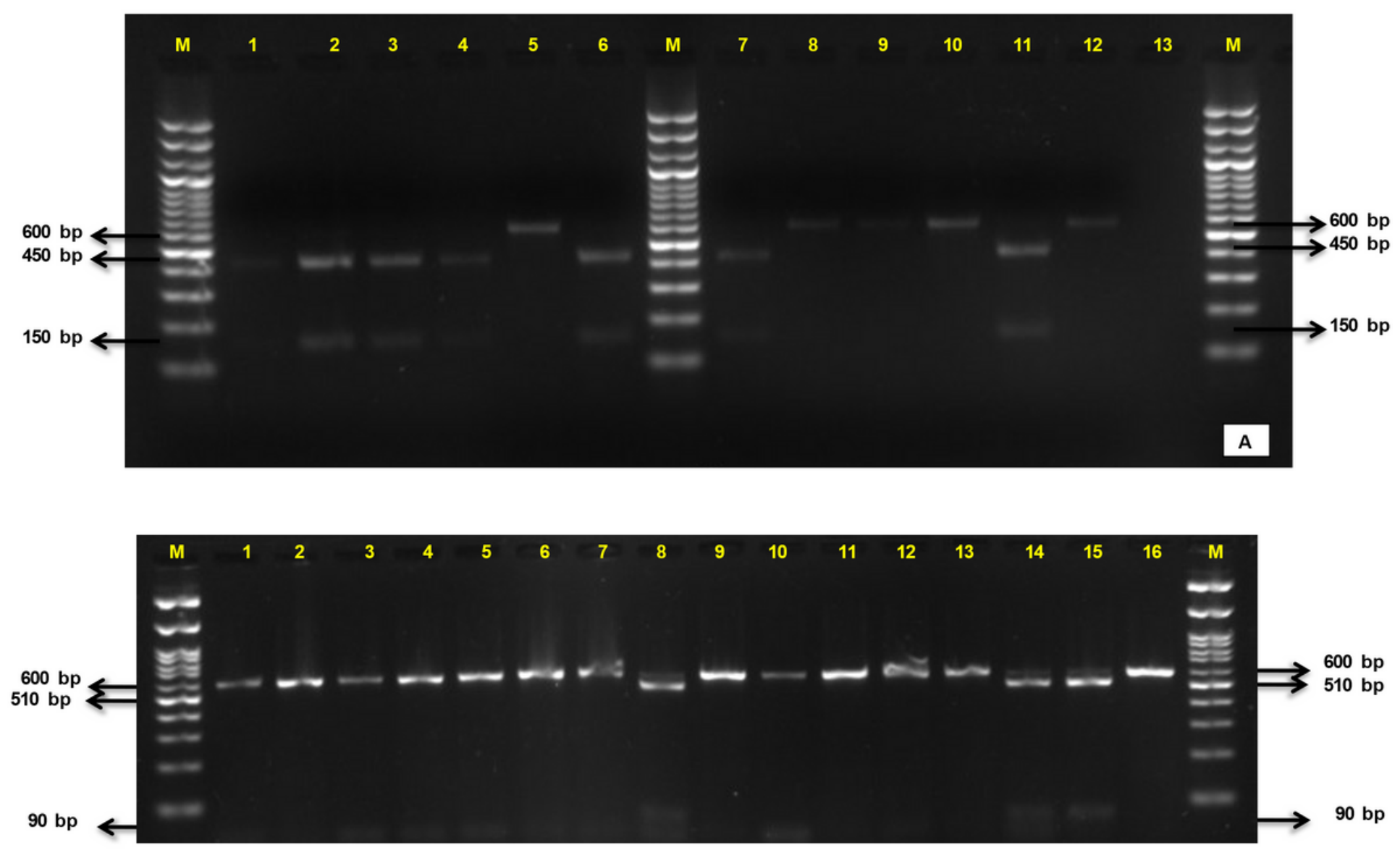

Fig. 2 PCR amplification of $\mathrm{COI}$ gene of S. frugiperda and digested with restriction enzymes, $\quad M s p l$ and Sacl

A. Sacl enzyme digested samples (Rice strain); (1 -4, 6, 7,11,=rice strains) 13 -Control) (without DNA)

B Mspl enzyme digested samples (Corn strain); ( 8,14 and 15 Corn strains) $600 \quad$ bp= uncut fragment; $M=$ molecular marker. (100 bp);

\section{Figure 2}

[See figure] 


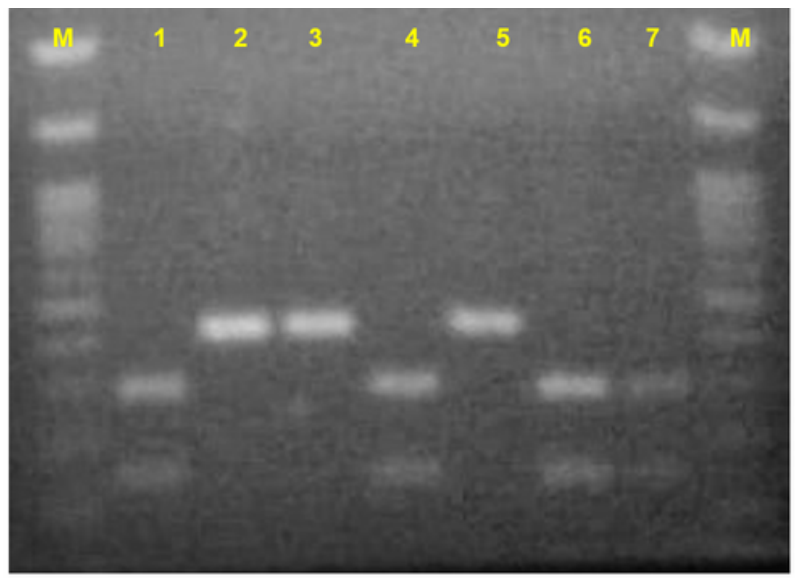

3a Rice strain (Chittorgarh (CTG))

AAAATATGCTGTACCAACAGGGTATTAAAATTTTTAGTTGATTAGCTACTTTCCATGGAACTCAAATCAATTATTCCCCATCTATTTTATGAAGATTAGGA TTTGTATTTTTATTTACTGTAGGGGGATTAACAGGTGTAATTTTATCTAATTCTTCTATTGATATTACTTTACATGATACTTACTATGTAGTTGCTCATTTC CACTATGTTTTATCAATAGGAGCTGTATTTGCTATTTTAGGTGGATTTATTCACT GATATC CATTATTTACTGGATTATCTTTAAATCCTTATATATTAAAA ATTCAATTTTTTATTATATTTATCGGAGTAAATTTAACTTTCTTCCCACAACATTTTTTTAGGATTAGCAGGTATACCTCGTCGATATTCTGAACTATCCTGA A

3b Corn strain (Dungarpur (DPR1))

ACAAATTTGCTGTCCACGGGTATTAAAATTTTTAGTTGATTAGCTACTTTCCATGGAACTCAAATTAATTATTCCCCATCTATTTTATGAAGATTAGGATTT GTATTTTTATTTACTGTAGGAGGATTAACAGGTGTAATTTTATCTAATTCTTCTATTGATATTACTTTACATGATACTTACTATGTAGTTGCTCATTTCCAT TATGTTTTATCAATAGGAGCTGTATTTGCTATTTTAGGGGGATTTATTCATTGATACCCATTATTTACTGGGTTATCTTTAAATCCTTATTTATTAAAAATT CTATTTTTTATTATATTTATCGGAGTAAATTTAACTTTCTTCCAACAGCATTTTTTAGGGTTATCAGGTATACCTGCGCGATATATGCGACTGTTCAGATA CATTAAAGTGTTTGTAGCATACATAGGCCGGCAGAATGATCACGTTAAAGAGTCCACNNCCNACGTACATTAAGTGCACAGGGGTAAAATGGATGATC AGAGCGTGCACATGCCTCAGAAGGTCAACTACTACTCGTTTCAAAACTCGATAATGATCCATCCTCAGGTTACTTTA

Fig. 3 Gel picture shows PCR amplification of ECORV digested COI gene ( region of S. frugiperda [Double band Rice strains: 1, 4,6,7); Single band Corn strains; 3 and 5) M -Marker 100 bp ladder; 5a- Sequence contains EcoRV recognition site; 5b- Sequence not contain EcoRV recognition site

\section{Figure 3}

[See figure] 